\title{
Patterning exergy of benthic macroinvertebrate communities using self-organizing maps
}

\author{
Young-Seuk Park ${ }^{a, *}$, Sovan Lek ${ }^{a}$, Michele Scardi ${ }^{b}$, \\ Piet F.M. Verdonschot ${ }^{c, 1}$, Suen E. Jørgensen ${ }^{d}$ \\ a LADYBIO, CNRS-Université Paul Sabatier, 118 route de Narbonne, 31062 Toulouse, France \\ b Department of Biology, University of Roma, Via della Ricerca Scientifica, 00133 Rome, Italy \\ c Alterra, Green World Research, Department of Freshwater Ecosystems, P.O. Box 47, 6700 AA Wageningen, The Netherlands \\ d Department of Environmental Chemistry, University of Copenhagen, Copenhagen, Denmark
}

\section{A R T I C L E I N F O}

Article history:

Published on line 28 December 2005

Keywords:

Trophical functional group

Ecological indicator

Water body types

\begin{abstract}
A B S T R A C T
Exergy is a measure of the free energy of a system with contributions from all components including the energy of organisms, and it is used as an ecological indicator. In this study, we implemented a self-organizing map (SOM) for patterning exergy of benthic macroinvertebrate communities. The datasets were extracted from the database EKOO consisting of 650 sampling sites in the Netherlands including 855 species. Using these datasets, exergy of five trophic functional groups (carnivores, detritivores, detritivore-herbivores, herbivores, and omnivores) were calculated for each sampling site on the basis of the biomass data. Exergy of each trophic group was used as input data of the SOM. By training the SOM the sampling sites were classified into five clusters and the classification was mainly related to water types of the sampling sites. Exergy of different trophic groups responded differently to different water types displaying characteristics of target ecosystems. Finally, the results show that exergy is an effective ecological indicator and patterning changes of exergy is an effective way to evaluate target ecosystems.
\end{abstract}

(c) 2005 Elsevier B.V. All rights reserved.

\section{Introduction}

Ecosystems are represented in diverse ways through the characteristics of their components. In aquatic ecosystems, the species composition of benthic communities depends on the diversity and stability of the aquatic habitats (Cummins, 1979; Ward and Stanford, 1979) that provide the possibilities of development (Malmqvist and Otto, 1987). Different species have different preferences for different environments at different scales. Therefore, information on the community structure can indicate the states of the respective ecosystems.
There are several approaches to describe a community structure such as habitat, trophic structure, functional feeding groups, etc. Among them, information on the trophic structure of the community reflects the effect of biotic interactions and energy flows, and complex interactions results from multiple pathways linking different ecosystem components (Carpenter, 1988).

Among various indicators suggested to describe ecosystem status (Mckenzi et al., 1992), exergy is a unique and efficient expression of energy status in ecosystems (Jørgensen, 1997; Jørgensen and Mejer, 1977). It is an effective measurement

\footnotetext{
* Corresponding author at: Department of Biology, Kyung Hee University, Dongdaemun-gu, Seoul 130-701, Republic of Korea. Tel.: +82 2961 0946; fax: +82 29610244.

E-mail addresses: parkys@khu.ac.kr (Y.-S. Park), lek@cict.fr (S. Lek), mscardi@mclink.it (M. Scardi), p.f.m.verdonschot@alterra.wag-ur.nl (P.F.M. Verdonschot), sej@dfh.dk (S.E. Jørgensen).

1 Fax: 31317424988.

0304-3800/\$ - see front matter @ 2005 Elsevier B.V. All rights reserved. doi:10.1016/j.ecolmodel.2005.11.027
} 
to represent the degree of accumulated energy through the development history of the target ecosystem. Thermodynamic definition of exergy is defined as the amount of work (entropyfree energy) a system can perform when it is brought to thermodynamic equilibrium with its environment (Jørgensen, 1997). The environment or reference state could be represented as the inorganic soup of the system without life. With this reference state the exergy measures directly the distance between the present state of the considered ecosystem and the thermodynamic equilibrium (Jørgensen, 1992; Jørgensen et al., 1995). Exergy in an ecosystem contents biogeochemical free energy and energy of organization information as quality function of the distance to the system in thermodynamic equilibrium at the same temperature and pressure but without life and information (Jørgensen, 1997; Debeljak, 2002). It is also considered as measure of the survival and growth of organisms and as measure of a general ecosystem state and development (Jørgensen, 1995; Debeljak, 2002).

Jørgensen et al. (2002) explained the structure of functional groups of benthic macroinvertebrates by a structurally dynamic model and the maximum exergy principle, and suggested the development of methods to incorporate the maximum exergy principle in the artificial neural networks (ANN) because structurally dynamic model is too time consuming to be applicable on a medium to large dataset covering many sites. As well documented, the complexity and non-linearity are generally embedded in ecological data resulted from interactions between different variables influencing the community structure (Legendre and Legendre, 1998; Lek and Guégan, 2000). Thus, with these non-linear ecological data, non-linear modelling methods such as ANNs should be preferred (Blayo and Demartines, 1991). ANNs were well applied for assessment of ecosystems (Chon et al., 1996; Dzeroski et al., 1998; Walley and Fontama, 1998; Schleiter et al., 1999; Walley and O'Connor, 2000; Park et al., 2003). Recently, attention has been given to community organization through unsupervised ANNs in diverse aspects (Lek and Guégan, 1999, 2000; Recknagel, 2002). Park et al. (2001) demonstrated that ANNs could be used for the changes in exergy as well as for extracting information on relations between community and exergy data. Through the learning process of the ANNs, we can define typical patterns playing a role as an actual entity in collectively representing communities of similar types, referred to patterning (Chon et al., 1996). Patterning exergy as ecological indicator in terms of thermodynamics may provide important ecological information to understand different ecosystems, and may be useful for the ecosystem management. Therefore, in this study, we consider the exergy at different trophic groups of benthic macroinvertebrates to characterize target systems using an artificial neural network. It could be a useful tool in managing aquatic ecosystems according to the EU Water Framework Directive (http://www.cordis.lu/fp5/).

\section{Methods}

\subsection{Ecological data}

The benthic macroinvertebrates dataset was extracted from the EKOO database in The Netherlands (Verdonschot and

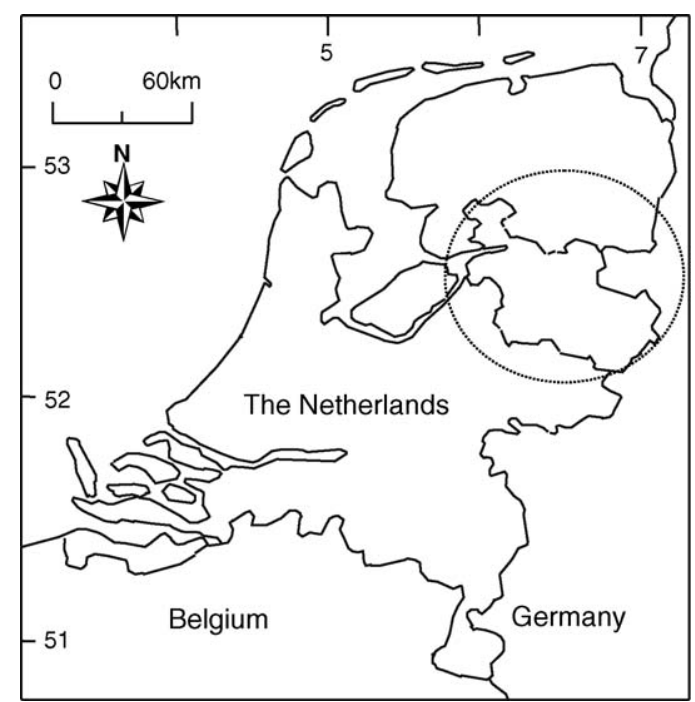

Fig. 1 - Sampling sites in the province of Overijssel, The Netherlands.

Nijboer, 2000). The data were collected at 650 sites of five different major water types in the province Overijssel from 1981 to 1985 (Fig. 1).

In the previous study, multivariate analysis techniques (cluster analysis and canonical ordination) were used to derive and describe site groups in terms of taxon composition and mean environmental conditions. These site groups resulted in 40 cenotypes (Verdonschot, 1990). The cenotypes were grouped into 12 categories according to similarities of ecological characteristics of sampling sites in five main water types (Table 1). The cenotypes describe the general characteristics, the macroinvertebrate species and the abiotic characteristics of groups. These characteristics are the most important starting point for water policy and management as they can be influenced directly (Heikens and van den Brink, 2001). In this study we consider the five major water types and

\begin{tabular}{llc}
$\begin{array}{l}\text { Table } \mathbf{1} \text { - List of water types sampled and number of } \\
\text { samples in each water type }\end{array}$ & \multicolumn{1}{c}{ Number of } \\
Water types & \multicolumn{1}{c}{ Sub-water types } & samples \\
\hline Helocrene springs (h) & Acid springs (As) & 9 \\
& Springs (Sr) & 52 \\
Streams (s) & Temporary streams (Ts) & 42 \\
& Upper watercourses (Uc) & 46 \\
& Stream pools (Sp) & 19 \\
Rivers and canals (r) & Middle watercourses (Mc) & 76 \\
& Lower watercourses (Lc) & 75 \\
& Canals (Ca) & 19 \\
Ditches (d) & Ditches (Di) & 125 \\
Lakes and pools (p) & Lakes (La) & 74 \\
& Ponds (Po) & 78 \\
Total & Moorland pools (Mp) & 35 \\
& & 650
\end{tabular}




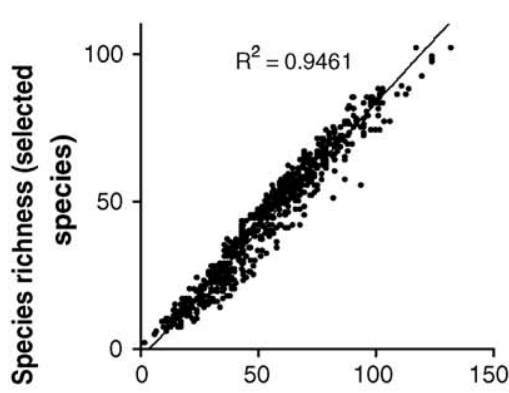

(a)

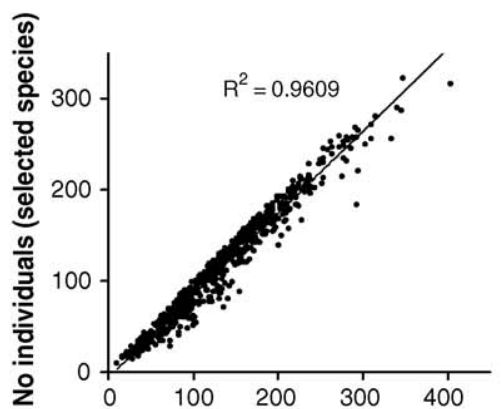

(b)

No individuals (overall)

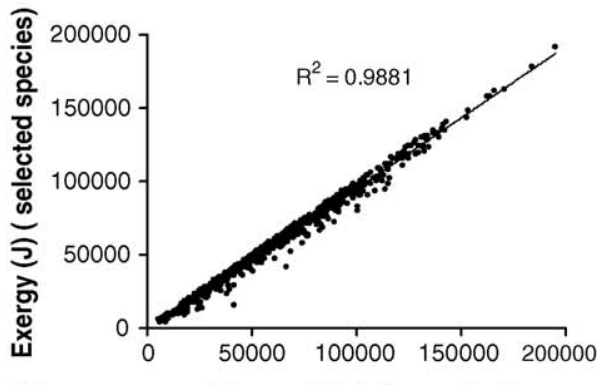

(c)

Exergy (J) (all species)

Fig. 2 - Relationships of communities of between 201 selected species and 885 all species: (a) species richness, (b) number of individuals, and (c) exergy.

their 12 subgroups. The general ecological characteristics of the EKOO database and the cenotypes have been reported in Verdonschot and Nijboer (2000).

From total of 854 species, mostly dominated by Chironomidae, Coleoptera, and Oligochaeta, 201 species were selected based on the occurrence frequency higher than $10 \%$ in all samples. Both the datasets of "all species" as well as the "selected species" showed high correlations with each other in species richness, density, and exergy $\left(R^{2} \geq 0.94\right.$, Fig. 2). Therefore, the new dataset with selected species well represents the overall communities.

From the community database, five trophic groups (carnivores, detritivores, detritivore-herbivores, herbivores, and omnivores) were extracted, and exergy was calculated for each group at each sampling site, and used as input data of the modelling. We calculated also a biodiversity using Shanon-Wienner's index at each sampling site to compare their properties as ecological indicators.

\subsection{Exergy}

Exergy represents the biomass of the system and the information that this biomass is carrying. It is possible, according to Jørgensen et al. $(2000,2002)$, to calculate the exergy (Ex) of the invertebrates as:

$\mathrm{Ex}=\sum_{i=1}^{n} \mathrm{~W}_{i} \mathrm{C}_{i}$

where $C_{i}$ is the concentration (biomass in this case) of the $i$ th state variable (i.e., selected species), $W_{i}$ is the information stored in the ith state variable, and $n$ is the number of variables. Exergy is expressed by this equation in detritus equivalent per liter; but multiplying by 18.7 it can be converted to $\mathrm{kJ} / \mathrm{l}$; see Jørgensen et al. (1995, 2000). The weighting factor expresses the information that each of the functional feeding groups carry by the genes. The weighting factors are unfortunately only known roughly because our knowledge to the genes of species is very limited. Furthermore, it is not possible to calculate the exergy of an ecosystem due to its very high complexity. It should therefore be stressed that the calculations only give an exergy index for a model of an ecosystem. The use of the weighting factors is however robust, as it has been possible to apply this approach successfully in structurally dynamic mod- elling (see Jørgensen et al., 2000, 2002). If the total biomass in the system remains constant through time, then the variation of exergy will be a function of only information embedded in the biomass (or the structure complexity of the biomass). It may be called specific exergy, expressed as exergy per unit of biomass (Marques et al., 1997). This specific exergy (SpEx) was also calculated from the exergy and biomass as following:

$\operatorname{SpEx}=\frac{\sum_{\mathrm{Ex}}}{\sum_{\mathrm{i}=1}^{n} C_{i}}$

In this study, data for benthic macroinvertebrate communities were used for calculating exergy at five different trophic functional groups. According to Park et al. (2001) and Jørgensen et al. (2002), the weighting factors applied for the functional feeding groups are: detritivores 30 , herbivores 35 , carnivores 47, detritivore-herbivores 32.5 and omnivores 41 .

The data consisted of five trophic groups were proportionally normalized between 0 and 1 in the range of the minimum and maximum values, and then used as input data in the modelling.

\subsection{Modelling process}

We used an unsupervised learning algorithm of artificial neural networks, a self-organizing map (SOM) (Kohonen, 1982, 2001), to pattern benthic macroinvertebrate communities in terms of thermodynamics. The SOM has found wide applications in the fields of data exploration, data mining, data classification, data compression, and biological modelling, due to its properties of neighbourhood preservation and local resolution of the input space proportional to the data distribution.

The SOM usually consists of input and output layers connected with computational weights (connection intensities). The array of input neurons (i.e. computational units) operates as a flow-through layer for the input vectors, whereas the output layer consists of a two-dimensional network of neurons arranged on a hexagonal lattice. The projection obtained by the incremental learning SOM algorithm, which is commonly used, is highly dependent on learning order of inputs. Consequently, fine classification is obtained for the latter inputs. Alternative method to overcome this fault is batch learning algorithm for constructing self-organizing map, which is used in this study. The batch computation version is significantly faster and does not require specification of any learning rate 
factor; therefore it has no convergence problems and yields more stable asymptotic values for the weight vector than incremental learning algorithm, and the results of the batch algorithm are not dependent on the learning order of inputs (Kohonen, 1998, 2001). The procedure can be described as followings:

1. Initialise the values of the weight vector $m^{*}$ by taking the first $K$ training samples, where $K$ is the number of weight vectors.

2. For each map unit $i$, collect a list of copies of all those training samples $x$, whose nearest weight vector belongs to unit i.

3. Take for each weight vector the mean over the union of the lists in $N_{i}$ according the following equation:

$$
m_{i}^{*}=\frac{\sum_{j} n_{j} h_{j i} \bar{x}_{j}}{\sum_{j} n_{j} h_{j i}}
$$

where the sum of $j$ is taken for all units of the SOM, or if $h_{j i}$ is truncated, over the neighbourhood set $N_{i}$ in which it is defined. For the case in which no weighting in the neighbourhood is used,

$$
m_{i}^{*}=\frac{\sum_{j \in N_{i}} n_{j} \bar{x}_{j}}{\sum_{j \in N_{i}} n_{j}} .
$$

The size of the neighbourhood set $N_{i}$ can be similar to the size used in the basic SOM algorithm.

4. Repeat on from point 2 several times until the solutions can be regarded as steady. In this study, the number of output neurons was set to $40(=8 \times 5)$ in $2 \mathrm{D}$ hexagonal lattice based on our experiences and a preliminary study. The detailed algorithm can be found in Kohonen $(1998,2001)$.

The training SOM results in a smoothing effect on the weight vectors of neurons (units). These weight vectors tend to approximate the probability density function of the input vector. Therefore weight vectors were visualized on the trained SOM map. It is efficient to understand the distribution pattern (and contribution to each unit) of each input variable (five trophic groups in this study) on the SOM map (Park et al., 2003).

We computed a quantization error and topographic error as evaluation criteria for resolution and topology preservation of the trained SOM, respectively. The former is the average distance between each data vector and its best matching unit (BMU) for measuring map resolution (Kohonen, 2001), and the latter represents the proportion of all data vectors for which first and second BMUs are not adjacent for the measurement of topology preservation (Kiviluoto, 1996). Thus, this error value is used as an indicator of the accuracy of the mapping in the preserving topology (Kohonen, 2001).

The learning process of the SOM was carried out using the SOM Toolbox (Alhoniemi et al., 1999) developed by the Laboratory of Information and Computer Science in the Helsinki University of Technology (http://www.cis.hut.fi/projects/somtoolbox/) in Matlab environments (The MathWorks, 2001) and adopted the initialization and training methods suggested by the authors that allow the algorithm to be optimized (Vesanto et al., 1999).

\section{Results}

\subsection{Exergy of benthic macroinvertebrate communities}

Exergy values calculated, using 201 selected species of benthic macroinvertebrates, amounted on average $62.0 \mathrm{~kJ}$ (S.E. 1.3) with in wide ranges of 3.7-191.1 kJ. For the different trophic groups, the mean exergy of detritivores was $23.2 \mathrm{~kJ}$ (S.E. 0.7, range 0.0-97.4) being the highest values for all groups, followed by herbivores with a mean of $15.4 \mathrm{~kJ}$ (S.E. 0.5, range 0.0-78.7), the omnivores $12.2 \mathrm{~kJ}$ (S.E. 0.8, range 0.0-89.3), the carnivores $8.2 \mathrm{~kJ}$ (S.E. 0.2, range 0.0-35.3), and the detritivore-herbivores $3.0 \mathrm{~kJ}$ (S.E. 0.1, range 0.0-19.0). Exergy calculated with the "selected species" dataset was highly correlated with that of the "all species" dataset displaying 0.9981 of regression determinant coefficient $\left(R^{2}\right)$ (Fig. $\left.2 c\right)$. This result shows that the dataset with selected species represents effectively the original dataset as also shown by the relationships in both species richness and total number of individuals (Fig. 2a and b).

Fig. 3 shows the variations of exergy, specific exergy, and the biodiversity index for different water types. Different letters on each chart stand for significant differences between water types $(p<0.05)$ based on Duncan's multiple comparison test using STATISTICA (StatSoft, 2001). Exergy values were low at acid springs, stream pools, canals, and moorland pools, which were significantly different from other types. Overall specific exergy also displays similar patterns compared
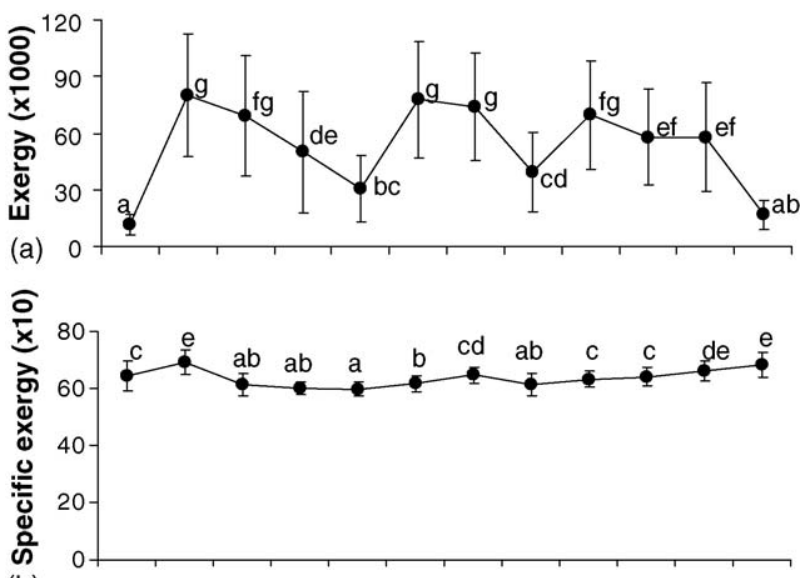

(b)

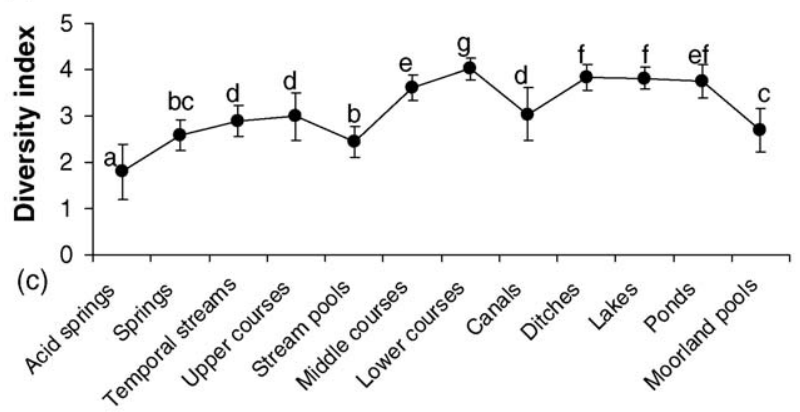

Fig. 3 - Comparison of exergy (a), specific exergy (b), and Shanon diversity index (c) at different water types. The same characters are not significantly different at the $5 \%$ level of confidence by using the Duncan's multiple comparison test. 
with exergy. However, the differences between water types are smaller than that of exergy, and specific exergy is very high at moorland pools and springs, while exergy and biodiversity index are low at both water types. Biodiversity index also displays different values at different water types. It is low at acid springs and moorland pools, while high at middle and low watercourses, lakes, ponds, and ditches. In considering the water velocity of each water type, exergy values were relatively high at lotic water types such as streams and middle and lower watercourses, whereas low at lentic types such as lakes and ponds. In contrast to exergy, biodiversity index was high at lentic types and low at lotic types.

\subsection{Patterning communities with SOM}

The learning process of the SOM converged very quickly in 16 iterations (4 in ordering phase and 12 fine tuning phase) with 0.210 of the quantization error and 0.083 of the topographic error representing the SOM was trained smoothly. On the SOM map, the benthic macroinvetebrate communities were patterned according to the similarities in exergy (Fig. 4a and b).

The units of the SOM map were classified into five different groups (I-V) based on a cluster analysis with the Ward algorithm (Fig. 4b). The unified distance matrix algorithm (U-matrix; Ultsch and Siemon, 1990; Ultsch, 1993) was also applied to find clusters on the SOM units, and it showed also similar results, although the results are not presented in the figure. Different grey scales or shaded types display different clusters on the SOM map (Fig. 4a). The size of the labels is proportional to the number of sampling sites in the same habitats, ranging from 1 to 28 sampling unites. Overall, the sampling sites from the same water types were assigned closely together on the SOM map. For example, pools and lakes (p) and ditches (d) are mainly located in the upper areas of the SOM map, helocrene springs (h) are in the lower right and in the mid left areas, streams (s) are in the left and in the lower areas on the SOM map, and rivers and canals ( $\mathrm{r}$ ) relatively scatter on the map, although they are showing weakly spread.

\subsection{Visualization of exergy of trophic groups}

The learning process of the SOM resulted in calculating connection intensities (weights) that represent a typical input vector for each of the input samples that fall into a particular SOM unit. In this study, connection weights represent estimated exergy of each trophic group in each SOM unit. Thus, it is helpful to visualize estimated exergy of each trophic group on the SOM map to evaluate the importance of each group at the sampling sites in each SOM unit. Fig. 5 shows the distribution of estimated exergy of each trophic group on the SOM map.

Dark represents high values of exergy, whereas light is low values. Overall, the mean values of exergy estimated by the SOM were similar to those of raw data. The estimated exergy of carnivores was on mean 7.8 kJ (S.E. 0.6, range 4.0-17.1), detritivores $26.3 \mathrm{~kJ}$ (S.E. 1.6, range 10.3-47.9), detritivore-herbivores
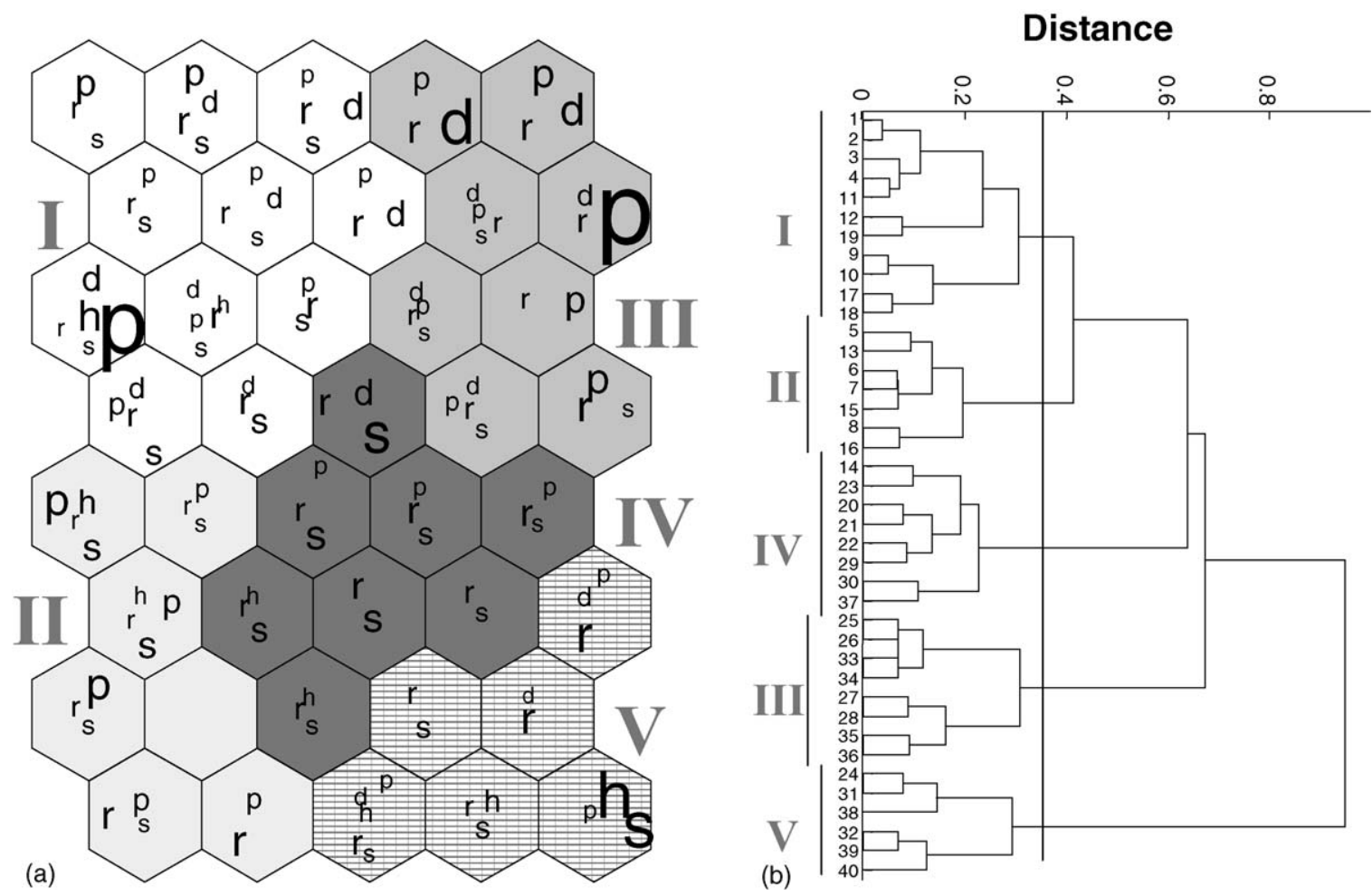

Fig. 4 - Classification of samples at five different water types on the SOM map trained with exergy of five trophic functional groups (a). Hierarchical cluster analysis with Ward algorithm with Euclidean distance measure was applied to cluster the SOM units (b). The Latin numbers (I-V) stand for different clusters. The labels in the hexagonal units represent different water types, and are given in Table 1. The size of the label is proportional to the number of sampling sites in the water types in the range of 1-35 samples. The Arabic numerals on the second column of dendrogram represent each unit of the SOM map from the upper left units to the lower right units. 

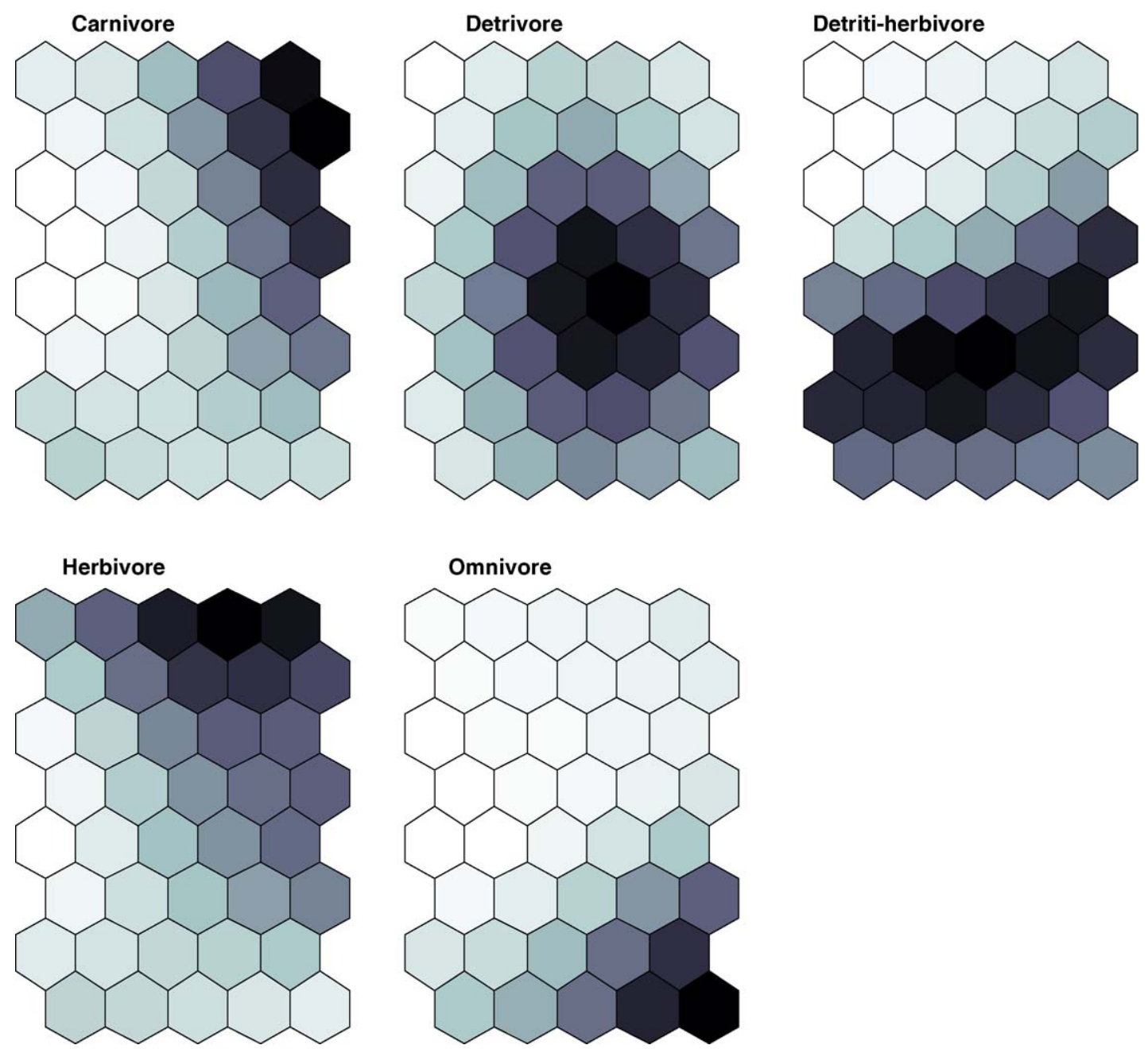

Fig. 5 - Visualization of the estimated exergy of trophic functional groups during the learning process of the SOM. Dark represents high values of exergy, whereas light is low values. The values were normalized between 0 and 1 to emphasize the relative importance of each group on the SOM map units.

$3.4 \mathrm{~kJ}$ (S.E. 0.3, 1.1-6.1), herbivores $14.9 \mathrm{~kJ}$ (S.E. 1.3, range 4.0-33.6), and omnivores $12.4 \mathrm{~kJ}$ (S.E. 2.4, range 1.2-60.8). Different trophic groups showed different distribution patterns on the SOM map. Carnivores and herbivores show high values in the upper right areas of the SOM map (cluster II) indicating relatively similar distribution patterns on the map $(r=0.78$, $p=0.000$ ). In detail, however, they display the different SOM units for the highest values. Detritivores are the highest in the middle areas (cluster IV) and detritivore-herbivores show the highest values in the lower areas (cluster II, IV, and V). Finally, omnivores show the highest values in the lower right areas displaying a clear gradient from the upper areas to the lower areas. This indicates that the omnivores observed were mainly assigned for the samples in the lower right areas of the SOM map (cluster V).

\subsection{Differences of exergy at different water types}

In the five main water types we considered 12 different subgroups of water types (Table 1). Considering the subgroups, they showed more clear distribution patterns on the SOM map.
Fig. 6 shows distribution of samples of the different water types. Samples from helocrene springs are divided into two subgroups of water types mainly based on the acidity: acid springs (As) and springs (Sr). Samples from As are mainly in the left areas of the SOM map, whereas samples from $\mathrm{Sr}$ are in the lower right areas (Fig. 6a). Sr is highly related to high exergy of omnivores, whereas As is relatively low exergy of all five trophic groups (Fig. 5).

Samples from streams consist of three subgroups of water types: temporary streams (Ts), upper watercourses (Uc), and stream pools (Sp). Samples are not mainly located in the right left areas on the SOM map (Fig. 6b). Samples of Ts are in the middle areas of the map, those of Uc are in the middle and upper areas, and those of Sp are in the upper left areas. Therefore, Ts is highly related to detritivores and detritivore-herbivores, and Sp to low value of overall exergy (Fig. 5). In particular no samples from springs and streams are assigned in the upper right and right areas of the SOM map (cluster III). This presents that the exergy of carnivores and herbivores are low in the water types of helocrene springs and streams. 


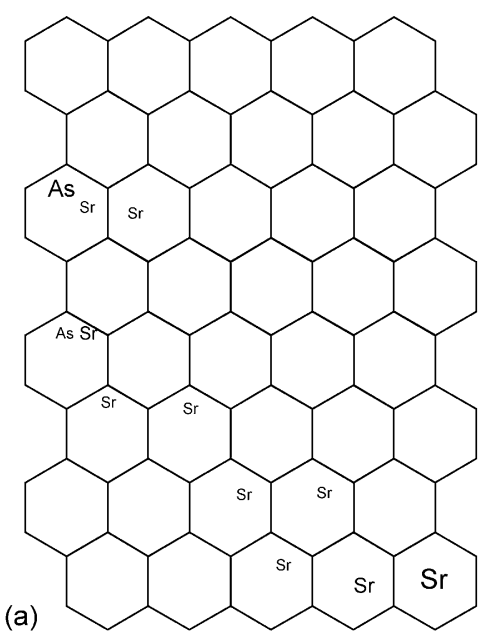

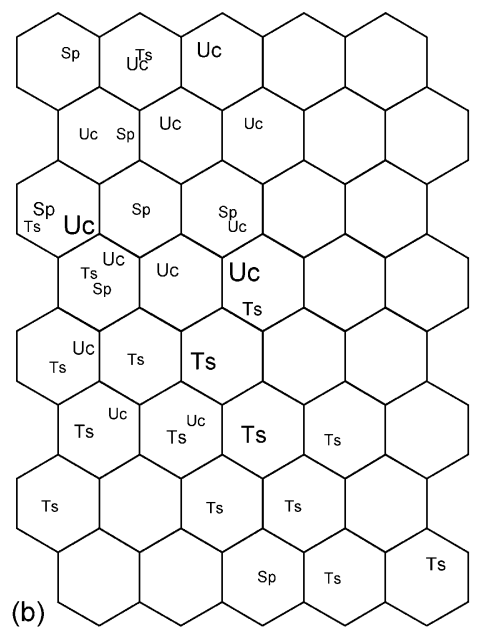

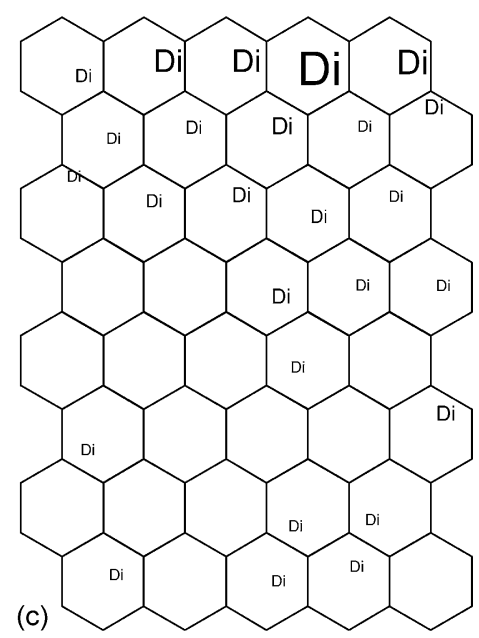

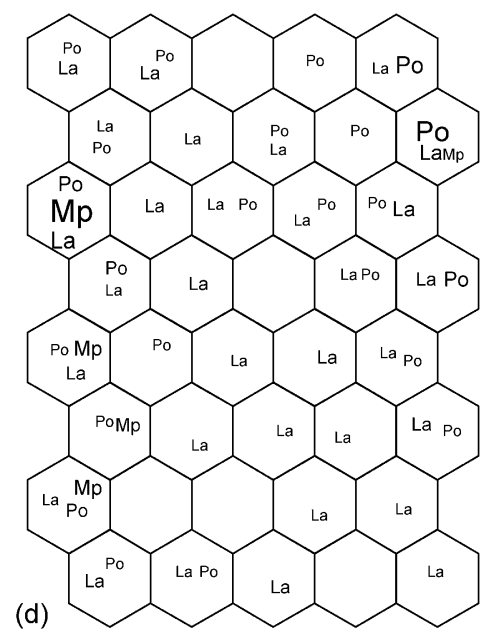

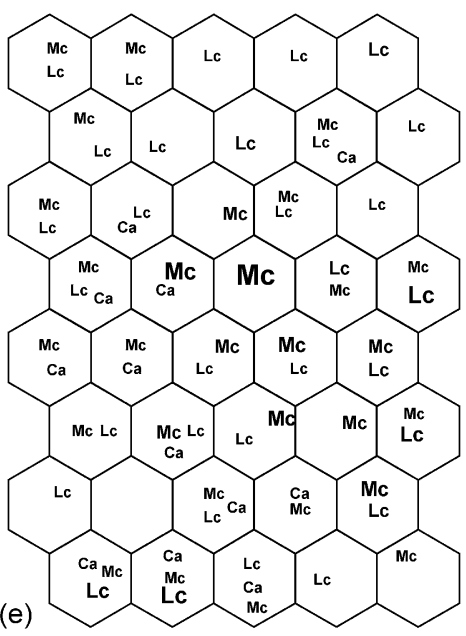

Fig. 6 - Distribution of sampling sites at different sub-water types on the SOM map trained with exergy of five trophic functional groups. Five water types in Fig. 4 are divided into corresponding groups of 12 sub-water types. (a) Helocrene springs, (b) streams, (c) ditches, (d) lakes and pools, and (e) rivers and canals. The labels in the hexagonal units represent sub-water types, and are explained in Table 1. The size of the label is proportional to the number of sampling sites in the water types in the range of 1-34 samples.

Samples in the ditches (Di) show high exergy of herbivores (and carnivores) as most samples are assigned for the upper right areas (Figs. 4 and 5c). They show also relatively low exergy of detritivore-herbivores, detritivores, and omnivores. This is comparable to those of helocrene springs and streams indicating high values of exergy in these groups.

Samples in pools and lakes are considered in three subgroups of water types: lakes (La), pools (Po), and moorland pools (Mp) (Fig. 6d). Samples of La scatter on the whole SOM units indicating that there are no specific types of exergy in trophic groups. However, samples from Po are mainly located in the upper right areas of the SOM map showing high exergy of carnivores mainly, although some samples in the left areas represents low exergy (Fig. 5). Samples of $\mathrm{Mp}$ are mainly assigned in the left areas of the SOM map. These left areas represent low exergy for each trophic group (Fig. 5).

Samples from rivers and canals are considered in three subgroups of water types: middle watercourses (Mc), lower watercourses (Lc), and canals (Ca). Canals are mainly in the left areas of the SOM map and some in the lower areas (Fig. 6e). This represents that the exergy of carnivores and herbivores were relatively low in this water type, while detritivores and detritivore-herbivores were relatively high (Fig. 5). Middle and lower watercourses scatter widely over the whole SOM units as like lakes, although they show relatively high frequencies in the middle areas.

\section{Discussion and conclusion}

In this study, exergy was calculated with benthic macroinvertebrate communities for different trophic groups, and then used for patterning samples through an adaptive learning algorithm, SOM. Exergy represents the amount of work a system can perform when it is brought to thermodynamic equilibrium with its environment. The environment or reference state could be represented as the inorganic soup of the system without life (Jørgensen, 1997). With this reference state the exergy measures directly the distance between the present 
state of the considered ecosystem and the thermodynamic equilibrium (Jørgensen, 1992, 1994, 1995, 1997; Jørgensen et al., 1995). The exergy includes both an energetic and information content embedded in the biomass, which has been estimated by the complexity of the organisms DNA (Marques et al., 1997; Fonseca et al., 2000). Thus, the exergy is correlated to amounts of biomass of organisms in the target ecosystems as shown in Christensen (1995).

We compared the differences of exergy, specific exergy, and biodiversity index at different water types (Fig. 3).

Exergy was low at acid springs, stream pools, canals, and moorland pools. However, biodiversity was not clearly different between water types. This represents exergy can differentiate more effectively the differences of communities of target ecosystems, although the biodiversity index does not distinguish the differences of communities. Specific exergy also shows similar patterns like exergy excluding temporary streams and moorland pools. They showed different behaviour in these water types. Therefore, exergy and specific exergy may be suitable alternatives, which could be used as goal functions in ecological models and as holistic ecological indicators of ecosystems integrity (Marques et al., 1997).

In the SOM map patterned with exergy of trophic groups, overall, the sampling sites from the same water types were assigned closely together. When we consider sub-water types, these patterns were even more clearly observed. This is due to the fact that different water types show different exergy of trophic groups. Springs are highly related to high exergy of omnivores, whereas acid springs show relatively low exergy of all five trophic groups. Temporary streams are highly related to detritivores and detritivore-herbivores, and stream pools to low value of overall exergy. Thus, helocrene springs and streams showed low exergy of carnivores and herbivores. The ditches showed high exergy of herbivores (and carnivores) and relatively low exergy of detritivore-herbivores, detritivores, and omnivores. This was comparable to those of helocrene springs and streams. Pools showed high exergy of carnivores mainly, and moorland pools expressed low exergy of each trophic group. Canals showed low exergy of carnivores and herbivores and relatively high exergy of detritivores and detritivore-herbivores. Meanwhile, lakes and middle and lower watercourses did not show any differentiations in exergy. Different sampling sites in these water types have apparently different trophic structures.

In considering exergy of trophic groups, we presented estimated exergy from the model on the SOM map in grey scale. From these maps, we can find the importance of each trophic group at different water types. For instance, carnivores and herbivores are relatively important in the water types pools and ditches, omnivores in the springs, and detritivore-herbivores in the temporary streams and canals. Finally, detritivores show relative importance in the temporary streams, middle watercourses, and canals, although they were abundant in most water types. This may be related to habitats of macroinvertebrates in regarding water types, because different water types provide different environmental conditions and organisms occupy their suitable habitats. These characteristics were effectively patterned through the SOM in this study.
In conclusion, exergy and specific exergy may be a suitable alternative, that could be used as goal functions in ecological models and as holistic ecological indicators of ecosystems integrity, and the patterning communities in terms of exergy is a very useful approach to understand and evaluate ecosystems using the SOM.

\section{Acknowledgements}

This work was supported by the EU project PAEQANN (EVK1CT1999-00026) and the Post-doctoral Fellowship Program of Korea Science \& Engineering Foundation (KOSEF).

\section{REFERENCES}

Alhoniemi, E., Himberg, J., Parviainen, J., Vesanto, J., 1999. SOM Toolbox 2.0, a software library for Matlab 5 implementing the self-organizing map algorithm. Online http://www.cis.hut.fi/projects/somtoolbox/.

Blayo, F., Demartines, P., 1991. Data analysis: how to compare Kohonen neural networks to other techniques? In: Prieto, A. (Ed.), Proceeding of the IWANN'91, International Workshop on Artificial Neural Networks. Heidelberg Springer, Berlin, pp. 469-476.

Carpenter, S.R. (Ed.), 1988. Complex Interactions in Lake Communities. Springer-Verlag, New York.

Chon, T.S., Park, Y.S., Moon, K.H., Cha, E.Y., 1996. Patternizing communities by using an artificial neural network. Ecol. Modell. 90, 69-78.

Christensen, V., 1995. Ecosystem maturity-towards quantification. Ecol. Modell. 77, 3-32.

Cummins, K.W., 1979. The natural stream ecosystem. In: Ward, J.V., Stanford, J.A (Eds.), The Ecology of Regulated Streams. Plenum Press, New York, pp. 7-24.

Debeljak, M., 2002. Applicability of genome size in exergy calculation. Ecol. Modell. 152, 103-107.

Dzeroski, S., Grbovic, J., Walley, W.J., 1998. Machine learning applications in biological classification of river water quality. In: Michalski, R.S., Bratko, I., Kubat, M. (Eds.), Methods and Applications of Machine Learning, Data Mining and Knowledge Discovery. John Wiley \& Sons, Chichester, pp. 429-448.

Fonseca, J.C., Marques, J.C., Paiva, A.A., Freitas, A.M., Madeira, V.M.C., Jørgensen, S.E., 2000. Nuclear DNA in the determination of weighing factors to estimate exergy from organisms biomass. Ecol. Modell. 126, 179-189.

Heikens, D.L.J., van den Brink, F.W.B., 2001. New tools for ecological water management in the province of Limburg (The Netherlands). In: Proceedings MTM-III-Tools for Ecological Water Management, pp. 125-131.

Jørgensen, S.E., Verdonschot, P., Lek, S., 2002. Explanation of the observed structure of functional feeding groups of aquatic macro-invertebrates by an ecological model and the maximum exergy principle. Ecol. Modell. 158 (3), 223-231.

Jørgensen, S.E., 1992. Parameters, ecological constraints and exergy. Ecol. Modell. 62, 163-170.

Jørgensen, S.E., 1994. Review and comparison of goal functions in system ecology. WIE MILIEU 44 (1), 11-20.

Jørgensen, S.E., 1995. The application of ecological indicators to assess the ecological condition of a lake. Lakes Reservoirs: Res. Manage. 1, 177-182.

Jørgensen, S.E., 1997. Integration of Ecosystem Theories: A Pattern, second ed. Kluwer, Dordrecht.

Jørgensen, S.E., Mejer, H.F., 1977. Ecological buffer capacity. Ecol. Modell. 3, 39-61. 
Jørgensen, S.E., Nielsen, S.N., Mejer, H., 1995. Emergy, environ, exergy and ecological modelling. Ecol. Modell. 77, 99-109.

Jørgensen, S.E., Patten, B.C., Straskraba, M., 2000. Ecosystem emerging IV: growth. Ecol. Modell. 126, 249-284.

Kiviluoto, K., 1996. Topology preservation in self-organizing maps. In: Proceedings of the ICNN'96, IEE International Conference on Neural Networks, IEEE Service Center, Piscataway, pp. 294-299.

Kohonen, T., 1998. The self-organizing map. Neurocomputing 21, 1-6.

Kohonen, T., 1982. Self-organized formation of topologically correct feature maps. Biol. Cybern. 43, 59-69.

Kohonen, T., 2001. Self-Organizing Maps, third ed. Springer, Berlin.

Legendre, P., Legendre, L., 1998. Numerical Ecology. Elsevier, Amsterdam.

Lek, S., Guégan, J.F. (Eds.), 2000. Artificial Neuronal Networks: Application to Ecology and Evolution. Springer, Berlin.

Lek, S., Guégan, J.F., 1999. Artificial neural networks as a tool in ecological modelling, an introduction. Ecol. Modell. 120, 65-73.

Malmqvist, B., Otto, C., 1987. The influence of substrate stability on the composition of stream benthos: an experimental study. Oikos 48, 33-38.

Marques, J.C., Pardal, M.A., Nielsen, S.N., Jørgensen, S.E., 1997. Analysis of the properties of exergy and biodiversity along an estuarine gradient of eutrophication. Ecol. Modell. 102, 155-167.

Mckenzi, D.H., Hyatt, D.E., Mcdonald, V.J. (Eds.), 1992. Ecological indicators, vol. 1 and 2. Proceeding of the International Symposium on Ecological Indicators. Elsevier Applied Science, Forth Lauderdale, FL.

Park, Y.-S., Céréghino, R., Compin, A., Lek, S., 2003. Applications of artificial neural networks for patterning and predicting aquatic insect species richness in running waters. Ecol. Modell. 160 (3), 265-280.

Park, Y.-S., Kwak, I.-S., Chon, T.-S., Kim, J.-K., Jørgensen, S.E., 2001. Implementation of artificial neural networks in patterning and prediction of exergy in response to temporal dynamics of benthic macroinvertebrate communities in streams. Ecol. Modell. 146 (1-3), 143-157.

Recknagel, F. (Ed.), 2002. Ecological Informatics: Understanding Ecology by Biologically-Inspired Computation.

Springer-Verlag, Berlin.
Schleiter, I.M., Borchardt, D., Wagner, R., Dapper, T., Schmidt, K.D., Schmidt, H.H., Werner, H., 1999. Modelling water quality, bioindication and population dynamics in lotic ecosystems using neural networks. Ecol. Modell. 120 (2-3), 271-286.

StatSoft, Inc. 2001. STATISTICA (data analysis software system), version 6. www.statsoft.com.

The MathWorks, Inc. 2001. MATLAB, version 6.0. Natik, Massachusetts.

Ultsch, A., 1993. Self-organizing neural networks for visualization and classification. In: Opitz, B., Lausen, O., Klar, R. (Eds.), Information and Classification. Springer-Verlag, Berlin, pp. 307-313.

Ultsch, A., Siemon, H.P., 1990. Kohonen's self organizing feature maps for exploratory data analysis. In: Proceedings of the International Neural Network Conference, Dordrecht. Kluwer, Netherlands, pp. 305-308.

Verdonschot, P.F.M., Nijboer, R.C., 2000. Typology of macrofaunal assemblages applied to water and nature management: a Dutch approach. In: Wright, J.F., Sutcliffe, D.W., Furse, M.T. (Eds.), Assessing the Biological Quality of Fresh Waters: RIVPACS and Other Techniques. The Freshwater Biological Association, Ambleside, Cumbria, pp. 241-262.

Verdonschot, P.F.M., 1990. Ecological characterization of surface waters in the Province of Overijssel (The Netherlands). PhD Thesis. Wageningen Agricultural University.

Vesanto, J., Himberg, J., Alhoniemi, E., Parhankangas, J., 1999. Self-organizing map in Matlab: the som toolbox. In: Proceedings of the Matlab DSP Conference, Espoo, Finland, pp. $35-40$.

Walley, W.J., Fontama, V.N., 1998. Neural network predictors of average score per taxon and number of families at unpolluted river sites in Great Britain. Water Res. 32 (3), 613-622.

Walley, W.J., O'Connor, M.A., 2000. Unsupervised pattern recognition for the interpretation of ecological data. Ecol. Modell. 146, 219-230.

Ward, J.V., Stanford, J.A., 1979. Ecological factors controlling stream zoobenthos with emphasis on thermal modification of regulated streams. In: Ward, J.V., Stanford, J.A (Eds.), The Ecology of Regulated Streams. Plenum Press, New York, pp. 35-55. 